\title{
The saga of lymph node surgery in malignant melanoma: a history repeating itself in gynecologic oncology
}

\author{
Virginie Bund $^{1,2}$, Lise Lecointre ${ }^{1,3,4}$, Chérif Akladios ${ }^{1,5}$ \\ ${ }^{1}$ Department of Gynecologic Surgery, Hôpitaux Universitaires de Strasbourg, Strasbourg, France; ${ }^{2}$ Laboratoire d'ImmunoRhumatologie Moléculaire, \\ Institut national de la santé et de la recherche médicale (INSERM) UMR_S 1109, Institut thématique interdisciplinaire (ITI) de Médecine de \\ Précision de Strasbourg, Transplantex NG, Faculté de Médecine, Fédération Hospitalo-Universitaire OMICARE, Fédération de Médecine \\ Translationnelle de Strasbourg (FMTS), Université de Strasbourg, Strasbourg, France; ${ }^{3}$ I-Cube UMR 7357 - Laboratoire des sciences de l'ingénieur, \\ de l'informatique et de l'imagerie, Université de Strasbourg, Strasbourg, France; ${ }^{4}$ Institut hospitalo-universitaire (IHU), Institute for Minimally \\ Invasive Hybrid Image-Guided Surgery, Université de Strasbourg, Strasbourg, France; ${ }^{5}$ I.R.C.A.D - Institut de Recherche contre les Cancers de \\ l'Appareil Digestif, Strasbourg, France \\ Contributions: (I) Conception and design: C Akladios; (II) Administrative support: None; (III) Provision of study materials or patients: None; (IV) \\ Collection and assembly of data: All authors; (V) Data analysis and interpretation: All authors; (VI) Manuscript writing: All authors; (VII) Final \\ approval of manuscript: All authors. \\ Correspondence to: Virginie Bund. Department of Gynecologic Surgery, Hôpitaux Universitaires de Strasbourg, 67000 Strasbourg, France. \\ Email: virginie.collin@chru-strasbourg.fr.
}

\begin{abstract}
In view of the high morbidity to complete lymphadenectomy, the sentinel node procedure is currently being investigated in different cancers with the aim of reducing morbidity and of achieving oncological outcomes similar to complete lymphadenectomy. In this review, a parallel will be drawn between the evolutions of the place of lymph node surgery in the management of melanoma and gynecologic cancers. Currently, in the case of cutaneous melanoma, the indications of lymph node surgery are becoming increasingly rare. In contrast with the scarce available evidence in gynecologic cancer, this trend is supported by multicenter randomized studies with a large number of patients for cutaneous melanoma. The second difference is the demonstrated therapeutic benefit of immunotherapies and targeted therapies in cutaneous melanoma, which are less significant in gynecological cancers for which the mainstay of treatment is surgery. According to this review, it seems that in gynecologic oncology, we could in the next decades follow the same pathway currently taken in the management of lymph nodes in malignant melanoma.
\end{abstract}

Keywords: Melanoma; gynecologic carcinoma; lymphadenectomy; sentinel lymph node dissection

Submitted Oct 12, 2020. Accepted for publication Jan 27, 2021.

doi: $10.21037 / \mathrm{cco}-20-227$

View this article at: http://dx.doi.org/10.21037/cco-20-227

\section{Introduction}

Radicality is a dogma in surgical oncology. It has been established for a long that prognosis is directly related to complete surgery leaving no residual tumor. After validation in penile cancers, sentinel lymph node biopsy (SLNB) indication was extended first to breast cancers by Giuliano et al. (1), then later to pelvic malignancies, by Echt et al. in 1999 for cervical cancers (2), by Burke et al. (3) in 1996 for endometrial cancers and in 1994 by Levenback et al. (4) for vulvar cancers. In this perspective, the significance of nodal disease and consequently the indication of surgical removal of regional lymph nodes is a central issue in the management of skin melanoma as much as in gynecologic malignancies.

\section{Surgical treatment of malignant melanoma}

In the surgical management of melanoma, a distinction must be made between two areas. On the one hand, there 
are the margins of resection of the tumor itself, which vary according to the thickness of melanoma. The current recommendations of wide local excision of primary tumours with $0.5 \mathrm{~cm}$ safety margins for in situ melanomas, $1 \mathrm{~cm}$ margin for tumours with a thickness of up to $2 \mathrm{~mm}$, and $2 \mathrm{~cm}$ for thicker tumours (5). According to the current ESMO's recommendations, reduced safety margins are acceptable in order to preserve function in acral and facial melanomas (6).

On the other hand, there is the size of the tumor which requires a complementary lymph node procedure. Regarding regional lymph nodes, SLNB is recommended for precise staging in melanoma of AJCC eighth edition stage $\mathrm{p}$ T1b or higher, i.e., with a tumour thickness $>0.8 \mathrm{~mm}$ (6) or with a tumour thickness of $<0.8 \mathrm{~mm}$ with ulceration (7). The improvement of knowledge concerning natural history has led to a continuous evolution of the indication, the extent and the technique of lymphadenectomy.

Scientific publications dating from the end of $18^{\text {th }}$ century have reported that melanoma progresses sequentially from primary site to the regional lymph nodes and then to more distant sites. Consequently, early removal of regional nodes could interrupt the metastatic cascade. Based on that, routine complete regional lymph node dissection (CRLND) was initially recommended in all patients presenting with malignant melanoma, even without clinical evidence of regional lymph node metastasis (8).

This aggressive and binary attitude has been contradicted by evidence. Indeed, regional lymphadenectomy is not associated with a substantial improvement in survival of the patients whatever the timing of its performance (primary or delayed).

In addition, Sim et al. (9) have shown in a prospective randomized study that $80 \%$ of patients undergoing CRLND have complications. The complications most commonly described were wound infection, chronic lymphedema, nerve injury and anesthetic complications (10). The total cost of care for melanoma patient's undergoing CRLND was at least fivefold the cost of wide excision only (10). The remaining $80 \%$ are exposed to a substantial risk of short and long term complications without any benefit in contrast only $20 \%$ of patients are expected to have metastases in the regional nodes $(9,11,12)$. In addition, if metastatic melanoma does not invariably spread first to the regional nodes, elective complete lymph node dissection (ECLND) may not be justified in all cases. The question that was raised at this point in time was: how could patients eligible for CRLND be identified? At the same time, the concept of SLNB that had been first investigated in penile cancer (13) began to emerge in stage I malignant melanoma cases (14) with the main objective to reduce surgical morbidity while achieving a similar oncological and outcome.

To answer the question, Morton et al. have conducted a prospective and multicenter study in order to evaluate the pertinence of SLNB in this indication (15). This study reported on 1,135 patients. SLNB was detected in 97\% of cases after a learning curve requiring 30 patients to reach this number. The authors concluded that SLNB is a feasible and reliable technique to select patients eligible for CRLND.

The next question then came, is CRLND always necessary when the SLNB are positive? A multi-center (41 centers), randomized study by Leiter et al. involving 5,547 patients was conducted to assess whether complete lymph node dissection resulted in increased survival compared with observation in patients with positive SLNB (16). 5,547 patients were enrolled. SLNB was positive in 1,269 (23\%) patients. Only 473 (39\%) of them signed up for randomization. Due to poor accrual and a low event rate the trial was prematurely closed. Two hundred and thirty-three patients were observed, and 240 patients had a CRLND. No difference in terms of progression-free survival (PFS), overall survival (OS) and distant metastasis was found.

In the light of these studies, even if SLNB is a feasible and valid technique for staging $(17,18)$, it has no impact on disease-specific survival. As a consequence, the current recommendation in the management of melanoma is that SLNB can be performed by a trained team in a highvolume facility, particularly if adjunctive systemic therapy is being considered or in a clinical trial, specifically when tumour thickness is superior to $0.8 \mathrm{~mm}$ or in the presence of ulceration with tumour thickness less than $0.8 \mathrm{~mm}$ ulceration (7). The surgical management of loco-regional melanoma was summarize in Figure 1 (6).

\section{Gynecologic malignancies}

\section{Focus on vulvar and vaginal melanomas}

Vulvar and vaginal melanomas are rare cancers of the female genital tract. They are at the border between skin and gynecological cancers. There is currently very little literature for these two pathologies due to their rarity. In case of vulvar melanoma, the two cut-off points described above for cutaneous melanoma regarding excision margins 


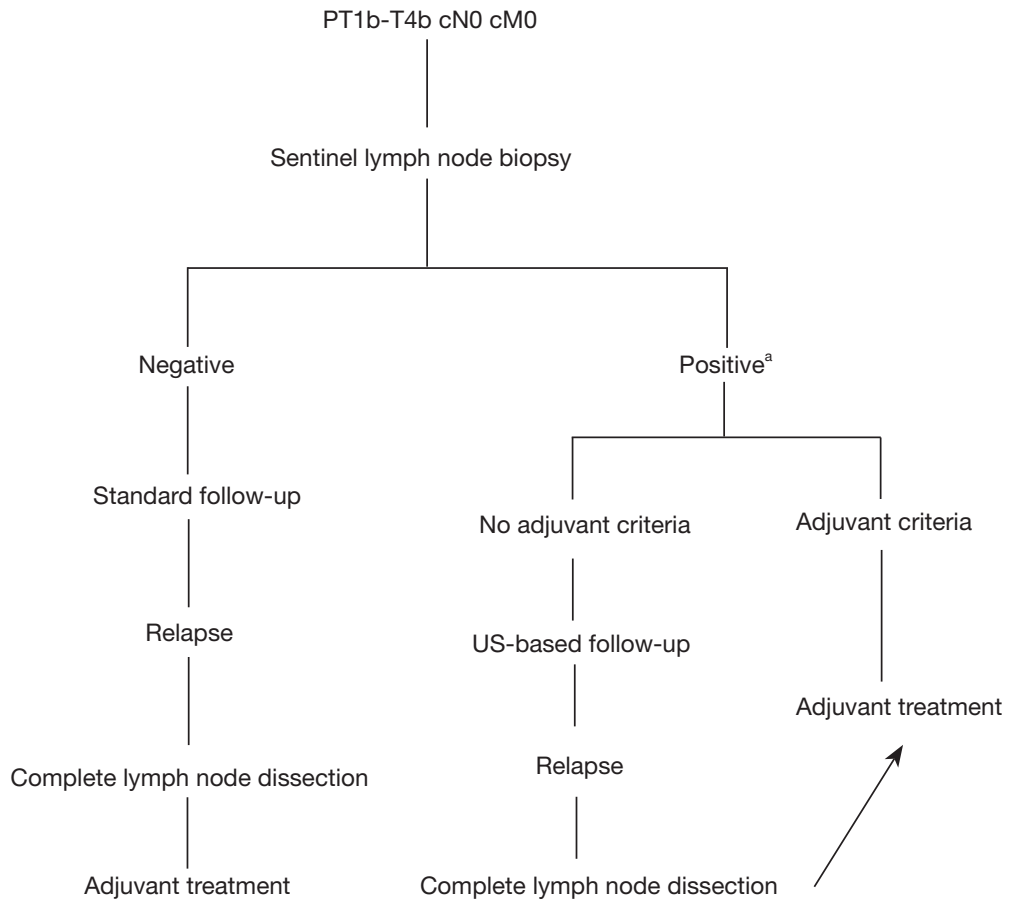

Figure 1 Treatment algorithm for stage I-III melanoma is based on ESMO recommendations (6). a, for positive sentinel lymph node biopsy patients, avoiding complete lymph node dissection is justified based on the results of the MSLT-II and DeCOG-SLT trials. US, ultrasound.

and the indication of SLN can be applied to vulvar melanomas. However, since the number of published studies about SLN procedures in vaginal cancers is fairly scarce, the role of SLNB and CRLND is still unclear. Consequently, the staging used by FIGO remains clinical (19).

\section{Focus on breast cancer}

In breast cancer, the finding of a positive SLNB was initially an indication to perform a CRLND. After it has been shown that additional axillary lymphadenectomy doesn't improve survival (20) the recommendations have changed and systemic axillary lymph node is no more indicated in these cases (21-23).

\section{Focus on gynecologic pelvic malignancies}

In gynecologic malignancies, like in melanoma, radical surgery of the primary tumor is the gold standard. This has been proven long time ago in ovarian cancer where the absence of residual tumor at the end of surgery was recognized as a major prognostic factor affecting OS and PFS (22-24). In early stages ovarian cancer, in endometrial and cervical cancer, lymphadenectomy carries, beyond tumor burden reduction, a staging role allowing tailoring of neo-adjuvant or adjuvant treatment. In this sense and for decades, lymphadenectomy (pelvic and in most of cases para-aortic) has been considered as a mainstay in the surgical management of all stages of ovarian cancer, endometrial cancer as well as cervical cancer in spite of its related operative and post-operative morbidity. Specifically, the incidence of lymphocele and lymphedema is of $38 \%$ and $20 \%$, respectively (27-29), the latter irreversibly altering the quality of life.

Only recently doubts have arisen after a few wellconducted randomized controlled studies failed to show a clear benefit in performing a systematic lymphadenectomy during gynecological cancer surgery (30).

In this context of doubt about the pertinence of systemic lymphadenectomy, SLNB might represent an alternative.

In pelvic malignancies, indications of SLNB as well as systemic loco regional lymphadenectomies are still evolving. There is evidence that sentinel lymph node status carries a prognostic significance. The rate of survival of patients with a negative SLNB is higher compared to patients with positive SLNB [90\% vs. $72 \%$, at five years respectively (31)], however until now, there is no available evidence in favor of a therapeutic role of SLNB or even 
loco regional lymphadenectomy in gynecologic pelvic malignancies.

\section{Conclusions}

It seems that we might be today at a preliminary stage of thinking concerning the potential role of both systemic loco regional lymphadenectomy and SLNB in pelvic gynecologic malignancies, while evidence has now set the stage in the management of melanoma. There is a definite need to address the most pertinent questions about the potential role of lymphadenectomies and SLNB in pelvic malignancies and to conduct large scale studies to provide answers in order to end up with robust recommendations, following the melanoma history.

\section{Acknowledgments}

Funding: None.

\section{Footnote}

Provenance and Peer Review: This article was commissioned by the editorial office, Chinese Clinical Oncology for the series "Sentinel Lymph Node Biopsy in Gynecologic Cancer". The article was sent for external peer review.

Conflicts of Interest: All authors have completed the ICMJE uniform disclosure form (available at http://dx.doi. org/10.21037/cco-20-227). The series "Sentinel Lymph Node Biopsy in Gynecologic Cancer" was commissioned by the editorial office without any funding or sponsorship. Dr. CA served as the unpaid Guest Editors of the series. The authors have no other conflicts of interest to declare.

Ethical Statement: The authors are accountable for all aspects of the work in ensuring that questions related to the accuracy or integrity of any part of the work are appropriately investigated and resolved.

Open Access Statement: This is an Open Access article distributed in accordance with the Creative Commons Attribution-NonCommercial-NoDerivs 4.0 International License (CC BY-NC-ND 4.0), which permits the noncommercial replication and distribution of the article with the strict proviso that no changes or edits are made and the original work is properly cited (including links to both the formal publication through the relevant DOI and the license).
See: https://creativecommons.org/licenses/by-nc-nd/4.0/.

\section{References}

1. Giuliano AE, Kirgan DM, Guenther JM, et al. Lymphatic mapping and sentinel lymphadenectomy for breast cancer. Ann Surg 1994;220:391-8; discussion 398-401.

2. Echt ML, Finan MA, Hoffman MS, et al. Detection of sentinel lymph nodes with lymphazurin in cervical, uterine, and vulvar malignancies. South Med J 1999;92:204-8.

3. Burke TW, Levenback C, Tornos C, et al. Intraabdominal lymphatic mapping to direct selective pelvic and paraaortic lymphadenectomy in women with high-risk endometrial cancer: results of a pilot study. Gynecol Oncol 1996;62:169-73.

4. Levenback C, Burke TW, Gershenson DM, et al. Intraoperative lymphatic mapping for vulvar cancer. Obstet Gynecol 1994;84:163-7.

5. Thompson JF, Scolyer RA, Kefford RF. Cutaneous melanoma. Lancet 2005;365:687-701.

6. Michielin O, Akkooi ACJ van, Ascierto PA, et al. Cutaneous melanoma: ESMO Clinical Practice Guidelines for diagnosis, treatment and follow-up †. Ann Oncol 2019;30:1884-901.

7. Han D, Zager JS, Shyr Y, et al. Clinicopathologic predictors of sentinel lymph node metastasis in thin melanoma. J Clin Oncol 2013;31:4387-93.

8. Snow H. Melanotic cancerous disease. Lancet 1892;2:1892-874.

9. Sim FH, Taylor WF, Ivins JC, et al. A prospective randomized study of the efficacy of routine elective lymphadenectomy in management of malignant melanoma. Preliminary results. Cancer 1978;41:948-56.

10. Urist MM, Maddox WA, Kennedy JE, et al. Patient risk factors and surgical morbidity after regional lymphadenectomy in 204 melanoma patients. Cancer 1983;51:2152-6.

11. Veronesi U, Adamus J, Bandiera DC, et al. Inefficacy of immediate node dissection in stage 1 melanoma of the limbs. N Engl J Med 1977;297:627-30.

12. Veronesi U, Adamus J, Bandiera DC, et al. Stage I melanoma of the limbs. Immediate versus delayed node dissection. Tumori 1980;66:373-96.

13. Cabanas RM. An approach for the treatment of penile carcinoma. Cancer 1977;39:456-66.

14. Morton DL, Wen DR, Wong JH, et al. Technical details of intraoperative lymphatic mapping for early stage melanoma. Arch Surg 1992;127:392-9. 
15. Morton DL, Thompson JF, Essner R, et al. Validation of the accuracy of intraoperative lymphatic mapping and sentinel lymphadenectomy for early-stage melanoma: a multicenter trial. Multicenter Selective Lymphadenectomy Trial Group. Ann Surg 1999;230:453-63; discussion 463-5.

16. Leiter U, Stadler R, Mauch C, et al. Complete lymph node dissection versus no dissection in patients with sentinel lymph node biopsy positive melanoma (DeCOG-SLT): a multicentre, randomised, phase 3 trial. Lancet Oncol 2016;17:757-67.

17. van der Vorst JR, Schaafsma BE, Verbeek FPR, et al. Dose optimization for near-infrared fluorescence sentinel lymph node mapping in patients with melanoma. Br J Dermatol 2013;168:93-8.

18. Stoffels I, Dissemond J, Pöppel T, et al. Intraoperative Fluorescence Imaging for Sentinel Lymph Node Detection: Prospective Clinical Trial to Compare the Usefulness of Indocyanine Green vs Technetium Tc 99m for Identification of Sentinel Lymph Nodes. JAMA Surg 2015;150:617-23.

19. Skanjeti A, Dhomps A, Paschetta C, et al. Sentinel Node Mapping in Gynecologic Cancers: A Comprehensive Review. Semin Nucl Med 2019;49:521-33.

20. Giuliano AE, McCall L, Beitsch P, et al. Locoregional recurrence after sentinel lymph node dissection with or without axillary dissection in patients with sentinel lymph node metastases: the American College of Surgeons Oncology Group Z0011 randomized trial. Ann Surg 2010;252:426-32; discussion 432-3.

21. Lyman GH, Somerfield MR, Bosserman LD, et al. Sentinel Lymph Node Biopsy for Patients With EarlyStage Breast Cancer: American Society of Clinical Oncology Clinical Practice Guideline Update. J Clin Oncol 2017;35:561-4.

22. Gradishar WJ, Anderson BO, Balassanian R, et al. NCCN Guidelines Insights: Breast Cancer, Version 1.2017. J Natl

Cite this article as: Bund V, Lecointre L, Akladios C. The saga of lymph node surgery in malignant melanoma: a history repeating itself in gynecologic oncology. Chin Clin Oncol 2021;10(2):21. doi: 10.21037/cco-20-227
Compr Canc Netw 2017;15:433-51.

23. Gnant M, Thomssen C, Harbeck N. St. Gallen/Vienna 2015: A Brief Summary of the Consensus Discussion. Breast Care 2015;10:124-30.

24. Stuart GCE, Kitchener H, Bacon M, et al. 2010 Gynecologic Cancer InterGroup (GCIG) consensus statement on clinical trials in ovarian cancer: report from the Fourth Ovarian Cancer Consensus Conference. Int J Gynecol Cancer 2011;21:750-5.

25. Bristow RE, Tomacruz RS, Armstrong DK, et al. Survival effect of maximal cytoreductive surgery for advanced ovarian carcinoma during the platinum era: a metaanalysis. J Clin Oncol 2002;20:1248-59.

26. Stoeckle E, Paravis P, Floquet A, et al. Number of residual nodules, better than size, defines optimal surgery in advanced epithelial ovarian cancer. Int J Gynecol Cancer 2004;14:779-87.

27. Kim SI, Lim MC, Lee JS, et al. Impact of lower limb lymphedema on quality of life in gynecologic cancer survivors after pelvic lymph node dissection. Eur J Obstet Gynecol Reprod Biol 2015;192:31-6.

28. Hayes SC, Janda M, Ward LC, et al. Lymphedema following gynecological cancer: Results from a prospective, longitudinal cohort study on prevalence, incidence and risk factors. Gynecol Oncol 2017;146:623-9.

29. Franchi M, Ghezzi F, Riva C, et al. Postoperative complications after pelvic lymphadenectomy for the surgical staging of endometrial cancer. J Surg Oncol 2001;78:232-7; discussion 237-40.

30. Harter P, Sehouli J, Lorusso D, et al. A Randomized Trial of Lymphadenectomy in Patients with Advanced Ovarian Neoplasms. N Engl J Med 2019;380:822-32.

31. Morton DL, Thompson JF, Cochran AJ, et al. SentinelNode Biopsy or Nodal Observation in Melanoma. N Engl J Med 2006;355:1307-17. 